\title{
Global Political Dynamics and the Science of Complex Systems
}

\author{
Hilton L. Root
}

\begin{abstract}
Do the complex dynamics of international relations resemble the longterm evolution observed in living systems? This chapter will try to identify the mechanisms associated with those dynamics, and to determine if the science of complex adaptive systems can aid in the understanding of international development.

It tries to address the weaknesses of current theories of international political economy to adequately explain global diversity and queries its empirical and theoretical limitations. Providing insight on the mechanisms by which divergence is a response to heightened interconnectivity, complexity theory offers a way to overcome the limitations of conventional political economy analysis.

We find that at a qualitative level the dynamics of the international system resemble known aspects of biological behaviour, speciation and intermittent behaviour. The next frontier for the study of social development is to find quantitative measures that define these processes.
\end{abstract}

\section{Introduction: Interaction, Co-evolution and Specialization as Sources of Diversity in Highly Interconnected Societies}

Global development is both a process and a condition according to most contemporary political economy analysis, and is attained via strategies of convergence with the successful models and strategies being held up as objects of emulation and imitation.

Convergence theory has characterised thinking in the developed West for more than half a century. It's underlying theoretical position is that irresistible forces are driving the world to converge towards an inevitable equilibrium state. Then the argument is that this equilibrium state will eventually be a world made up of liberal capitalist democracies like those in Western countries such as the USA. This chapter will question the underlying assumption of inevitable convergence to a global optimum. It will show the destructive power of convergence strategies as

H.L. Root $(\bowtie)$

Schar School of Policy and Government, George Mason University, 3351 Fairfax Drive, Arlington, VA 22201, USA

e-mail: hrootz@gmv.edu 
seen today in the perplexing conflicts in the Middle East following well-meant but massively disruptive interventionist military policies by Western powers that did not produce the anticipated balance of political and economic development. In today's far-from-equilibrium world a new theoretical underpinning is urgently required to address the short and long-term problems ahead. It will be argued that the dynamic perspective of complex systems provides that underpinning [17].

At the end of the Cold War, systematically describing modernisation as a process of convergence, gained considerable validation from empirical trends such as the collapse of the Soviet Union, the structural crisis of Swedish socialism, the reversal of French socialism, and democratic movements in the Confucian domains of East Asia. In 1989, when Francis Fukuyama declared history to be over, the global hegemony of democracy and market economies seemed certain to continue. ${ }^{1}$

In the teleological logic of modernisation theory countries in transition could only go in one direction, toward liberal democracy, its rivals on the world stage being routed.

Since 9/11 contrary empirical evidence has accumulated. Contemporary global political economy is increasingly defined by diversity and both the process and the end point of development are contested: the presumption that there is no alternative to liberal democracy seems discredited. There is no longer a consensus on what economic, social and cultural variables development refers to, or what the process of attaining it is. Living standards are rising in many regions without the accompanying features of modernisation. In countries as diverse as China, Saudi Arabia, Russia, Singapore, and Turkey the economic gap with the West is closing but not the gap in political order. Living standards are converging but progress on political liberty is scant. A China that enjoys the advantages of international law and organisation continues to contest the legitimacy of liberal internationalism's core values. Market rules and economic competition do not ensure the rest of the modernisation sequence will follow. Regime diversity not only persists but new forms of governance not known during the cold war period have appeared. Much of the former Soviet Union has lapsed into authoritarian governance. Political Islam has arisen in an economically open Turkey and is spreading throughout the Middle East. New forms of democracy have little in common with prior variants.

\footnotetext{
${ }^{1}$ Twenty-five years after proclaiming history to have ended, Francis Fukuyama has not blinked; writing in the Wall Street Journal (2014) [4] he concedes it's not the 'end of history' yet. Models of national development that have a strictly materialist focus that seem robust today will ultimately lose their appeal, failing to address the inherent human drives for recognition and self-expression. Even China, the 'single most serious challenge to liberal democracy in the world today' [3, pp. 56-57] he predicts will converge, its path will be multigenerational, taking more time than originally anticipated - nevertheless inevitable. No matter how effectively its one party state fulfils materialistic needs, its failure to satisfy other universal needs will make its influence on the world stage transitory: 'The emergence of a market based global economic order and the spread of democracy are clearly linked. Democracy has always rested on a broad middle class and since the ranks of prosperous, property-holding citizens have ballooned everywhere ... Once societies get up the escalator of industrialisation, their social structure begins to change in ways that increase the demands for political participation'.
} 
Increasingly regimes that call themselves democratic lack traits that are essential to a democracy, such as competitive, multiparty elections, competitive political parties, free speech, the right of assembly, an independent judiciary, and a free media. The behaviour of the middle classes in many of the world's emerging urban clusters is short-term and authoritarian rather than equitable, sustainable or participatory. Economic strategies that raise living standards often defy the logic of successful patterns of the past.

The dominant paradigms in global political economy do not effectively describe these patterns of diversity. Modernisation theory can explain some global convergence but not the prevalence of different paths to the modern world with its many variations of democracy and authoritarianism. All of these trends raise a simple question: is the system of international relations entering a period of hectic reorganisation and does anyone really know which way developing countries are trending?

\section{Global Political Economy and Development}

Yet, convergence to a global liberal democracy remains a core organising principle in global political economy and defines a normal and healthy process of socioeconomic development in most theories of global development. Its pervasiveness is assured when concepts from microeconomics are applied to the study of international systems. Microeconomics postulates that growth occurs as more efficient technology, institutions, regulations or firms supplant less efficient variations. It predicts that competition will direct policy to the same set of optimised solutions, prompting societies to evolve towards the same end point or fitness peak. Encouraged by the pressures of external competition, firms and governments facing the same optimisation problems will select the same sets of solutions and will organise production according to a single optimum that represents the global peak.

The most cohesive statement of convergence is modernisation theory. It addresses not only the system of production but politics and individual behaviour and it offers a view of social change that links a nation's economic growth with its receptivity to liberal values: as societies industrialise, urbanise and prosper, experiencing convergence towards a free market economy, they will also converge to optimal forms of democratic governance. ${ }^{2}$

\footnotetext{
${ }^{2}$ Theories of interdependence in global political economy link the proliferation of liberal regimes to enduring stability, and link increased economic exchange and interconnectedness to peace. They date to the European Enlightenment of the eighteenth century and are frequently associated with Emanuel Kant's (1795) notion of 'perpetual peace'.But they have been the bedrock of US foreign policy and have defined US engagement with the world since the time of Jefferson's presidency (1801-1810). With the exception of the Eisenhower (1953-1961), Nixon (1969-1974) and Ford (1974-1977) administrations, post World War II foreign policy has actively sought
} 
As populations become wealthier, urbanised, and educated 'political development' would direct countries away from authoritarian and towards more democratic forms of organisation. Convergence theory made a comeback as a popular quasiscientific theory in the post cold-war political and economic climate. The collapse of the centrally planned economies in the Middle East, India and the demise of the Soviet Union all seem to lend it renewed validation. Its projections of eventual convergence are closely linked to liberal institutionalism and its notions of building a more humane and stable world than that projected by power politics approaches. ${ }^{3}$ In retrospect the modernisation sequence it anticipates seems to have been based on a parochial selection of cases.

The most sophisticated formulation of convergence theory is neoclassical institutionalism, e.g. the Oxford Handbook of Political Economy defines its subject matter to be 'the methodology of economics applied to the analysis of political behaviour and institutions' [22, page 3]. It conceives of a natural continuum initiated by external competition or global competitiveness that runs from economic rationality, to the design of optimal forms. The strong pull of a single attractor or best way ensures a smooth transition process [2]. ${ }^{4}$ But if the agents all follow a rational decision-making behaviour to maximise their goals, then why is institutional adaptation rarely a smooth process?

\section{Political Science and International Political Economy}

The global quest for economic development is central to the study of political economy, but falls between two subsidiary branches of Political Science. International relations is that sub-discipline that deals explicitly with the interactive relations among states and it is where the methodology to examine the systemic relations of states is elaborated, and where the varieties of state behaviour are studied in relation to each other. It covers both 'power in the system', who has influence over system dynamics and structure; and the 'power of the system' over its constituent parts; it seeks to understand how different configurations of states, networks of norms, trade and the linkages between military power and industrialisation effect outcomes.

\footnotetext{
global convergence toward liberal values in the hope of facilitating cooperation and rendering the international system less anarchic.

${ }^{3}$ Liberal institutionalism explores how self-interested parties can cooperate on the basis of rules and norms when there is no central authority. It is often identified with the writings of Keohane [10]. It has influenced scholars of international relations to explore the many ways that institutions can help overcome barriers to cooperation.

${ }^{4}$ External competition, in a global environment of market liberalism will drive all firms and nations, to similar regulatory structures, similar standard of living and eventually similar systems of domestic governance. To attain this peak, the best organisational norms will be selected; the convergence of productive capacity will produce convergent living standards, which will create a global middle class with the same culture of efficiency and the same aspirations for democratic participation.
} 
Assessing the differences among the politics of countries is the central concern of another branch, comparative politics. Challenges to the convergence hypothesis in global political economy are much more likely to arise from within comparative politics. It is rich in case studies that reveal the durability of distinct institutional and social configuration. Hence its practitioners are unlikely to be surprised by the persistence of diversities within countries, across countries and regions, and over time. Some of the best comparative work reveals why a great deal of diversity is still observable despite the deepening of globalisation and the frequent cross-national diffusion of ideas and behaviours [11]. In the narratives constructed by comparativists, transition processes are rarely smooth and the path toward development is without a fixed end point or best way. But because these conclusions are embedded in many different cases and arrived at inductively, research in comparative relations is less likely than international relations to shape the theories about interactions or system-level patterns. ${ }^{5}$

Comparative politics distinguishes rival forms of democracy and illuminates the trade-offs in the range of variations and political responses to opportunities and challenges. Comparativists methodically study how interests, identities and institutions at the country level produce particular developmental trajectories. But they are unified more by a common method than by a shared theory of global order or the change processes that shape it. While revealing the endless possibilities that arise from the detailed interactions between local political and economic institutions, it often takes the broader context of globalisation as given. It is not the place to find general principals for the overall dynamical behaviour of evolution in the global system. It does not separate the dynamical features of a regime's evolution or fitness from the nature of the ecology created by the system's co-evolutionary dynamics. The answer to why and how diversity is a consequence of increased interactions in that system must be sought elsewhere.

The study of the political economy of development falls into the gap that exists within political science between international relations and comparative politics, leaving both without a plausible explanation for the observed variation. Political scientists that try to take into account the connection between international and domestic politics have insufficient theory to explore this connection.

To fill this gap we will explore whether regularities observed from the study of Complex Adaptive Systems, can also be applied to the properties, behaviours, interactions, and dynamics in the evolving system of international relations. Do the evolutionary dynamics found in the complex adaptive systems created by nature match the processes of complexity in the global economy?

Complexity science shares a number of important values with comparative politics. Both address how feedback shapes interactions among agents in a local environment, and both explore the interactive feedbacks of local actions on the global context. Comparativists also highlight the path dependent properties of

\footnotetext{
${ }^{5}$ International relations theorists are more likely than comparativists to use 'large $n$ ' statistical investigations, to determine a proposition's applicability to a wide number of cases.
} 
national legacies, and seek to explain why new norms and social values do not necessarily replace the old, but evolve through adaptation. Nevertheless, complexity science goes further in elucidating mechanisms of change, and rigorously specifying the relationship between diversity and interconnectivity.

\section{The Evolutionary Dynamics of Densely Connected Societies}

Research by complexity theorists reports that the dynamics of a living ecology is strongly influenced by the system's complexity. A critical pattern in natural ecologies is that interconnectivity increase species abundance. Because the individual characteristics of a species are coupled with its environment instead of convergence towards the fittest or most complex form there is co-evolution between species. This same pattern can be observed among nations that share high volume of trade in goods and services [17, pp. 165-216].

Evolutionary systems are comprised of parasitic, predatory and collaborative relationships. As the pace of interconnectivity increases, the number of successful mutations will also increase. This in turn, accelerates responses among neighbouring systems, causing an increasing degree of differentiation to occur and these differences foster responses that move the system into a new basin of attraction. There is no equilibrium, the system's coevolutionary dynamics produce regular change cycles. Fluctuations caused by interactions can trigger a switch from one stable period to another [6]. Intermittency is a fundamental property of the evolutionary dynamics of complex systems in nature that are found as well in man-made systems. Bifurcation and intermittent behaviour in the global system are closely related since they change each other as they interact. Seemingly stable systems can be interrupted by sudden shifts to an alternative state.

\section{The Behavioural Mechanisms of Policy Diffusion: Decision-Making, Collective Learning and the Persistence of Objectively Inferior Choices}

Essential to understanding a system's evolutionary dynamics are the underlying behavioural mechanisms. In convergence theory the underlying motivation is emulation and imitation of the fittest designs. The principal streams of positive political economy assume that policy-making involves a search for a single solution that is objectively better than its alternatives. This implies that social institutions and policies came into being because the individuals who introduced them applied relevant information to fixed preferences, weighed the alternatives, and then selected optimal choices, calculating the future course of their actions with full knowledge of 
costs and benefits. It assumes that agents are fully rational and act on full knowledge of the future consequences of their actions, including the responses of other agents.

The assumption that individuals are fully rational and always choose the optimal solution is not realistic. Human rationality and cognition is bounded, asserts organisational theorist and Noble Laureate Herbert Simon. Decision-making by individuals is limited by the quantity of information they can gather, their finite information-processing capacity, and the amount of time they have to make a decision. To avoid information overload, people seek solutions that are satisfactory rather than optimal: they satisfice rather than optimise [19-21]

Convergence theories of global development also presume that the mechanisms of collective learning by imitation will ensure that the norms and institutions of the most successful nations are the most likely to be copied. This idea, which has been a staple of international relations theory since the European Enlightenment of the eighteenth century, is often associated with Kant's (1795) 'Perpetual Peace' [7].

But copying has many psychological motivations beyond top-down emulation. People may decide to copy just in order to remove the burden of basing their choices on a thoughtful assessment and a comparison of options. British economist Paul Ormerod makes this original proposition in Positive Linking [14] where he shows that copying may reduce the likelihood of a qualitatively better result. This is because copying is the way individuals in social networks gain confidence in their decisions, hence they are more likely to copy familiar examples, those closest to their own circumstances rather than highly successful models, regardless of whether they are making the best decision. Thus, when individuals copy they reduce the range of available options and increase the likelihood that they will select objectively inferior alternatives. This increases the probability that bad choices will proliferate. However, copying provides a practical heuristic for making acceptable decisions.

The development of norms, policies and institutions through copying is far more complex than convergence theory shows. For an optimal model to influence behaviour depends is not just a question of demonstrating the most effective of several solutions: it depends also on interactions and the choices made by the actors with whom one may interact.

Imitation of peers is a response to uncertainty that may help to explain the overwhelming empirical evidence that income convergence does not correct macrolevel imbalances among nation states [15]. Economists sometimes explain the observed pattern of divergence with the idea of conditional or club convergence in which countries that share intrinsic characteristics tend to cluster around a living standard that is specific to their cluster while different clubs converge to a local standard, divergence between clubs dominates the macro pattern. Ormerod's notion that people imitate those most like themselves can be an exclusionary mechanism that bars members of clubs from converging to the higher living standards of alternative clubs. 


\section{Parallel Processing}

If agents make decisions totally independently from each other then convergence is more likely to emerge, but in environments of complex interdependence and interaction agents conduct parallel processing: each agent acts both independently, in pursuit of their own advantage, and also interdependently, as they react to and produce adaptive responses in their neighbours. Agents make their decisions simultaneously, both influencing and limiting others' actions (parallel processing). This makes it difficult to identify cause-effect relationships and explain how one variable can affect another. The need for such processing increases with the frequency of interaction. When multiple agents engage in parallel processing, they can change the behaviour of the whole system.

\section{Fitness Landscapes: How Ecology Affects Decision-Making}

Fitness landscapes are a metaphor that can apprehend how the topographic contours of a local ecology can shape the formation of priorities. It is widely used in evolutionary biology to help to visualise how the reproductive success of various populations depends on the properties of their respective environments.

The peaks on a fitness landscape represent highest fitness, valleys the lowest; landscapes vary in their degrees of ruggedness. If the landscape is smooth there will be an unlimited view of the horizon, all paths will lead to the highest peak, and all populations can conclude their adaptive searches at the same end point, or global peak, regardless of their starting point or selected path.

However, on rugged landscapes the many local peaks may conceal the highest peaks, and only some paths lead to the highest fitness. A population can end up on a local peak and never be able to find the global peak. Since no two landscapes are rugged in the same way, populations facing different landscapes are unlikely to evolve the same way: adaptive climbs on local peaks involve different degrees of difficulty and offer different perspectives of the wider landscape. Evolutionary outcomes on different landscapes will lead to non-convergent variation; this same logic can be applied to international relations. If the populations are countries that do not begin their fitness walks from the same starting points they are unlikely to end up at the same end point or global peak. Due to the different topological impediments that arise from fitness landscapes of differing degrees of ruggedness not all populations will see the same set of alternatives. Thus populations that share a landscape or ecology will not necessarily have the same number of good designs or policy options to choose from. Differences that can be traced to the initial starting point will motivate leaders to optimise (or satisfice), on differing dimensions. 


\section{Niche Construction Theory: Global Development Through Variation}

Analogies of the process of niche construction in evolutionary biology challenge another pillar of convergence theory in social evolution. Niche construction theory explores how local resource distribution in an ecosystem alters subsequent evolution. Each species tries to survive by creating or defending its own niches, a specific set of biological traits that enables it to exploit the resources of the environment.

Biologists observe that in densely connected ecosystems niche construction increases the number of genotypes able to thrive in a particular environment.This finding has relevance for both theories of economic growth and for the system of international relations. Both envision a process with competition among many providers leading toward the same end point or fitness peak. More efficient social technology, institutions, regulations or firms would supplant variations that are less efficient at providing the market, consumers or regimes with the optimised products it demands.

But if we analogise from what happens in natural systems from increased interaction and interconnectedness the result is unlikely to be towards a common optimal framework of institutions and values. Instead in a highly interdependent environment, niche construction multiplies the existence of groups with wellseparated traits. Each new niche that is created can foster the possibility of a new set of interactions and exchanges with a multiplier effect that encourages new specialisations and refinement of existing strategies, organisations and institutions. Thus, the optimal strategy for evolution is not to delete but to increase variety.

As market size increases, niche construction by one group seeking to alter its environment to its own specification creates new adaptive possibilities, through co-evolution, variation and specialisation with a multiplier effect that leads to an increasing diversity. ${ }^{6}$ As interrelatedness associated with globalisation increases, many co-evolutionary niches that form networks of interactions result. For example, the experience of South Korea's large export-oriented chaebols exemplifies how a country can attain global competitiveness by strengthening local institutional uniqueness. Oligopolistic insulation from competition at home generates surplus revenues that are used to respond competitively to global prices.

Our analogy with natural ecologies leads to the hypothesis that the growing density of global connectivity associated with globalisation will enable diverse populations to succeed because they are well adapted to a particular environment, rather than because they represent the most optimised or best set of institutional

\footnotetext{
${ }^{6}$ Complexity theorists, like [5], a computer scientist, and [8, 9], an evolutionary biologist, explain growth and change in social systems by niche construction. They contend that a global economy powered by accelerated interconnectivity will not drive all societies to an optimum value or set of structures, but with more nodes, fosters an increasing number of intersections that can create a combinatorial explosion of possibilities.
} 
arrangements. We conclude that for global political economy convergence is just one option.

\section{Convergence is Just One Option}

This elaboration on how species in ecological systems co-evolve by selforganisation, variation and specialisation rather than top-down control or bottom-up mimicry, has significant implications for understanding the probability of convergence toward optimal designs in human societies. Our analysis first explores the linkages of individual decision-making and collective learning and finds that together they are likely to result in cognitive processes that may lead to non-optimal outcomes. Then we observe that in both social and natural systems, diversity results from the coevolutionary interaction and increased connectivity in global networks.

What complexity science can contribute to the study of global politics is insight about the ways the local resource distribution in an ecosystem can alter subsequent evolution and how developmental processes within a population (microevolution) can influence evolutionary change at a system level (macro-evolution).

Applying complexity theory to global political economy we speculate that processes of interaction, co-evolution and specialisation in a highly interconnected global society can produce behaviours and institutions that operate far from the optimum and that can persist for decades and centuries. A global economy powered by accelerated interconnectivity will not drive all societies towards a common or optimal set of institutions. Complexity theory emphasises external competition will stimulate trial and error processes that take place in a local context, and give rise to myriad hybrid outcomes. Accordingly, convergence towards a liberal model that encompasses free market economies and democratic governance appears to be just one of the possible options among the many trends in global development.

This insight runs contrary to conventional models of modernisation that presume the competitive pressures of globalisation will delete deviations from 'best practice' driving all economies to produce the same optimised set of goods and all polities to adapt to the same optimised rules and regulations and it leads us to suggest strategies for evolutionary stability that are at variance with much contemporary global policy.

\section{Evolutionary Stables Strategies in Political Economy: What Should Global Public Policy Optimise?}

Convergence theory gained policy relevance at the outset of the Cold War as part of a search for a non-communist alternative to development that would safeguard the stability of the system of international relations and assist in the struggle against insurgency. It attained prominence in political economy at time when 
both scholars and the public debated the changing role in global affairs of the newly independent nations. Initial evidence for the theory was based primarily on anecdotal methodology. As their reference point they had in mind the success of the Marshall plan in reversing the tide of communism in post-war Europe and from the apparent success of the allies in establishing stable democracies in Germany and Japan.

Scientific validation came later from studies conducted by economists such as W.W. Rostow seeking consistent and universal laws of development [18]. These studies argue consistently that democratisation is an inevitable and possibly necessary stage for economic growth to fully materialise. However, the studies rarely explored the role of contact with peers among would be developing nations. They took an essentially top-down perspective both within nations and among nations that is understandable when global trade was predominantly North-South, and when global elites had often been educated by the nations that they were colonised by. Expectations for the future trajectory of developing nations were premised upon observations from a relatively small sample size of already industrialised nations.

Rising powers today have different expectations and see post-World War II developments from a different perspective. The convergence of Germany and Japan to liberal norms occurred at the expense of their sovereignty being clipped by immersion in international arrangements and occupying troops stationed on a semi-permanent basis. Rising powers like China or India do not want to end up as semi-sovereign states denied the possibility of exercising international power warranted by their distinct economic success. This difference in perspectives between rising and incumbent powers has significant implications for the future of global order.

Although it does not sit well with emerging powers convergence theory continues to resonate with the conceptions and aspirations for global stability of the incumbents. It gains enough scientific rigour from statistical regressions to appear scientific to specialists familiar with only the view of one discipline, able to see only one dimension of the problem of development.

Political economists of all persuasions continue to assert that without convergence to liberal institutions, economic development will produce stunted and dysfunctional nations that are inherently unstable. ${ }^{7}$ Convergence theory is also endorsed by more culturally oriented analysis. Scholars that emphasise values and the role of culture such as Fukuyama assert that convergence conforms to instinctual and irresistible psychological forces and therefore represents a necessary and normal sequence of social development. ${ }^{8}$ The introduction of complexity theory to considerations of global development will open a debate over what development policy should optimise. Economics defines optimisation as seeking

\footnotetext{
${ }^{7}$ Frequently cited examples are [12, 13] and [1].

${ }^{8}$ Political scientists do not always specify what quantity or values the system of international relations can or should optimise. Those inspired or reliant on the judgment of economists prioritise efficiency, but realists and constructivists generally tend to have different priorities.
} 
the most efficient path to a fixed end point. Its faith in objective 'best practices' nurtures a belief in the inevitable triumph of liberal market democracy as a global norm-setter. This sets global development a challenge of correcting inferior choices (digressions from optimality) in which catching up means copying and imitating. Complexity framed international relations theory, by contrast, will seek a balance between order and disorder in a symbiotically evolving environment and stresses the role of experimentation adaptability, resilience, collective learning and collective problem solving.

Complexity science suggests that benchmarking that tries to match a country's evolutionary fitness with strategies of incumbent powers, or that searches for best practice, increases the risks to global stability. It warns us that aiming for homogeneity may drive out healthy diversity from the global system. If all countries pursue efficiency and use the same criterion to define it, this is likely to undermine system level resilience and reduce the prospects for evolutionary periods of stable growth. ${ }^{9}$

Acknowledgements Colleagues and students at the Department of Political Economy, King's College, London, (2013-2014) provided continuous stimulation during the writing of this paper. Paola Zambano was a valuable research assistant. The Erasmus Mobility Fund supported her work. The ideas were presented at various venues including the 'Political Economy Graduate Seminars' Institute for Economic Affairs, UK; Centre for Research in Social Simulation, University of Surrey, UK; INET Seminar Series of the Institute for New Economic Thinking, Oxford Martin School, UK; European Bank for Reconstruction and Development (EBRD), UK; School of Physics and Astronomy, University of Manchester, UK; Centre for Complexity Science, Imperial College London, UK; World Interdisciplinary Network for Institutional Research Conference, Greenwich, UK; Economics and International Studies Seminars, University of Buckingham, UK; Robert Axtell, Eric Beinhocker, Erik Berglöf, Stephen Davies, Doyne Farmer, Nigel Gilbert, David Hales, Jeffrey Johnson, Terence Kealey, Alan McKane, Paul Ormerod, and Aris Tantidis commented at various stages. I thank them all.

Open Access This chapter is distributed under the terms of the Creative Commons Attribution 4.0 International License (http://creativecommons.org/licenses/by/4.0/), which permits use, duplication, adaptation, distribution and reproduction in any medium or format, as long as you give appropriate credit to the original author(s) and the source, provide a link to the Creative Commons license and indicate if changes were made.

The images or other third party material in this chapter are included in the work's Creative Commons license, unless indicated otherwise in the credit line; if such material is not included in the work's Creative Commons license and the respective action is not permitted by statutory regulation, users will need to obtain permission from the license holder to duplicate, adapt or reproduce the material.

\footnotetext{
${ }^{9}$ A failure that may arise from efforts to copy the developmental trajectories of the most successful, such as the White Revolution launched by the Shah of Iran, may have an injurious impact on domestic stability [16].
} 


\section{References}

1. Acemoğlu, D., Robinson, J.A.: Why Nations Fail: The Origins of Power, Prosperity, and Poverty. Crown, New York (2012)

2. Boyer, R., Drache, D. (eds.): States Against Markets: The Limits of Globalization. Routledge Studies in Governance \& Change in the Global Era. Routledge, London (1996)

3. Fukuyama, F.: The Origins of Political Order: From Prehuman Times to the French Revolution. Farrar, Straus \& Giroux, New York (2011)

4. Fukuyama, F.: At the 'End of History' Still Stands Democracy. The Wall Street Journal, New York (2014). http://www.wsj.com/articles/at-the-end-of-history-still-stands-democracy1402080661

5. Holland, J.H.: Complexity: A Very Short Introduction. Oxford University Press, Oxford (2014)

6. Jensen, H.J.: Self-Organised Criticality: Emergent Complex Behavior in Physical and Biological Systems. Cambridge Lecture Notes in Physics. Cambridge University Press, Cambridge (1998)

7. Kant, I.: Perpetual Peace: A Philosophical Essay (1795). Classic Reprint, Forgotten Books, London (2012)

8. Kauffman, S.A.: The Origins of Order: Self-Organisation and Selection Evolution. Oxford University Press, New York (1993)

9. Kauffman, S.A.: At Home in the Universe: The Search for Laws of Self-Organisation and Complexity. Oxford University Press, Oxford (1993)

10. Keohane, R.O.: Atfer Hegemony: Cooperation and Discord in the World Political Economy. Princeton University Press, Princeton (1984)

11. Kupchan, C.A.: No One's World: The West, the Rising Rest, and the Coming Global Turn. Oxford University Press, New York (2012)

12. North, D.C.: Understanding the Process of Economic Change. Princeton University Press, Princeton (2005)

13. North, D.C., Wallis, J.J., Weingast, B.R.: Violence and Social Orders: A Conceptual Framework for Interpreting Recorded Human History. Cambridge University Press, Cambridge (2009)

14. Ormerod, P.: Positive Linking: How Networks Can Revolutionise the World. Faber \& Faber, London (2012)

15. Pritchett, L.: Divergence Big Time J. Econ. Perspect. 11(3), 3-17 (1977)

16. Root, H.: Aliance Curse: How America Lost the Third World. Brookings Institution Press, Washington, DC (2008)

17. Root, H.: Dynamics Among Nations: The Evolution of Legitimacy and Development in Modern States. MIT Press, Cambridge, MA (2013)

18. Rostow, W.W.: The Stages of Economic Growth: A Non-Communist Manifesto. Cambridge University Press, Cambridge (1960)

19. Simon, H.: The Sciences of the Artificial. MIT Press, Cambridge, MA (1969)

20. Simon, H.: Theories of bounded rationality. In: McGuire, C.B., Radner, R. (eds.) Decision and Organisation. North-Holland, Amsterdam (1972)

21. Simon, H.: Models of Bounded Rationality, vols. 1 \& 2. MIT Press, Cambridge, MA (1982)

22. Weingast, B.R., Wittman, D.A. (eds.): The Oxford Handbook of Political Economy. Oxford University Press, Oxford (2006) 